\title{
CRÍMENES INTERNACIONALES Y DERECHOS HUMANOS: PAPEL DE LA CORTE PENAL INTERNACIONAL
}

\author{
Alfredo Etcheberry* \\ Universidad de Chile, Chile \\ aetcheberry@egb.cl
}

Distinguidos colegas, estimados estudiantes:

He aceptado gustosamente la invitación que se me ha formulado para intervenir con una ponencia en la vertiente de este Congreso relativa a la "Corte Penal Internacional: realidad y desafíos", que cobra particular importancia para nosotros, dada la reciente -y tardíaratificación por Chile del Estatuto de Roma y la precedente incorporación a nuestro derecho penal interno de los delitos de genocidio, crímenes de lesa humanidad y crímenes de guerra.

1. Ante todo, corresponde dejar sentado que la Corte Penal Internacional no es un tribunal dedicado primordialmente a la protección de los derechos humanos y la sanción de sus violaciones. Otras instituciones judiciales internacionales cumplen esa misión: específicamente la Corte Interamericana de Derechos Humanos y la Corte Europea de Derechos Humanos. El propósito de la Corte Penal Internacional aparece afirmado en su Preámbulo con las siguientes palabras:

“... Teniendo presente que en este siglo millones de niños, mujeres y hombres han sido víctimas de atrocidades que desafían la imaginación y conmueven profundamente la conciencia de la humanidad... Afirmando que los crímenes más graves de trascendencia para la comunidad internacional en su conjunto no deben quedar sin castigo... Decididos a poner fin a la impunidad de los autores de esos crímenes y a contribuir así a la prevención de nuevos crímenes... Decididos... a establecer una Corte Penal Internacional de carácter permanente, independiente y vinculada con el sistema de las Naciones Unidas que tenga competencia sobre los crímenes más graves de trascendencia para la comunidad internacional en su conjunto... Decididos a garantizar que la justicia internacional sea respetada y puesta en práctica en forma duradera...”.

Profesor de Derecho Penal, Universidad de Chile. Master of Comparative Law. Doctor "Honoris Causa", Universidad de Talca. Chile. 
$\mathrm{Y}$ en su articulado reafirma estos propósitos, especialmente en sus arts. $1^{\circ}, 5^{\circ}, 7^{\circ} \mathrm{y}$ $8^{\circ}$, que definen su competencia ratione materiae.

2. Puede verse, por consiguiente, que el objetivo de la Corte es el de sancionar crímenes, pero solo los más graves y siempre que estén específicamente comprendidos dentro de la competencia de la Corte, con la exigencia adicional de que sean extendidos en cuanto a las personas afectadas y prolongados en el tiempo. Además, tanto el Preámbulo como el articulado afirman y desarrollan el principio de la complementariedad del Estatuto de la Corte con respecto a las jurisdicciones nacionales, específicamente, del Estado en cuyo territorio se haya cometido el crimen de que se trate o del Estado del que sea nacional el acusado del crimen, si lo hay.

Si alguno de esos Estados ya ha juzgado o está juzgando la misma situación que pudiera caer bajo la competencia de la Corte, aquel Estado tendrá preferencia para que se reconozca la sentencia ya dictada o se respete su derecho exclusivo a seguir investigando y juzgando. Pero la competencia de la Corte prevalecerá cuando el Estado en cuestión no esté dispuesto a llevar a cabo la investigación o no esté en capacidad o situación de hacerlo; o bien el juicio en el Estado competente obedeciera en realidad al propósito de sustraer al acusado de su responsabilidad penal o no hubiere sido instruido el juicio en forma independiente e imparcial de conformidad con las garantías procesales reconocidas por el derecho internacional.

Todas estas materias son objeto de un examen llamado de admisibilidad. La propia Corte podrá examinar la admisibilidad y deberá cerciorarse de su competencia; además, el acusado y el Estado que tenga jurisdicción en la causa podrán impugnar la admisibilidad o la competencia de la Corte.

Pero en consonancia con todo lo expuesto inicialmente, existe todavía otro motivo para declarar la inadmisibilidad, que deberá ser examinado por la Corte y además podrá ser invocado por los otros titulares de la petición de inadmisibilidad: conforme al art. 17, letra (d), se podrá declarar la inadmisibilidad de un asunto, cuando este "no sea de gravedad suficiente para justificar la adopción de otras medidas por la Corte". Esta calificación, por cierto, se hace sobre la base de la información de que se dispone en la Corte, generalmente reunida por el fiscal.

3. Con lo que llevamos dicho, hay tres cuestiones que deben tenerse siempre presentes al formarse opinión sobre la función y eficacia de la Corte:

a) Que la Corte no es un tribunal para velar en términos generales sobre los derechos humanos, sino para castigar crímenes;

b) Que tampoco cualquier crimen que por su naturaleza caiga bajo la competencia de la Corte es juzgado por esta, sino cuando reviste caracteres de la mayor gravedad; y 
c) Que el Estatuto reconoce el derecho preferente de juzgar a los Estados en que se cometieron los delitos o de los cuales son nacionales los imputados, salvo que esos Estados no quisieran procesar, o no estuvieren en condiciones de hacerlo, o lo hubieren hecho o estuvieren haciéndolo para evitar que un acusado sea juzgado por la Corte o al revés, sin condiciones de imparcialidad y adecuada defensa.

4. Con este marco conceptual, no hay duda de que el Estatuto de la Corte está estrechamente vinculado a los derechos humanos, ya que los crímenes de su competencia tienen precisamente como bien jurídico protegido los derechos humanos más importantes recogidos en las declaraciones universales, internacionales o regionales de mayor relevancia, y muchos de ellos han sido además objeto de convenciones o declaraciones internacionales en particular. Así ocurre con el delito de genocidio (art. $6^{\circ}$ del Estatuto), cuyas cinco hipótesis representan violaciones de derechos garantizados en la Declaración Universal de Derechos Humanos, el Pacto Internacional de Derechos Civiles y Políticos, la Convención Americana sobre Derechos Humanos (o Pacto de San José), y respecto del cual tiene vigencia la Convención Internacional para la Prevención y Sanción del delito de genocidio, suscrita en 1948. Lo mismo puede decirse de todas las hipótesis consideradas como crimenes de lesa humanidad (art. 70 del Estatuto): las allí contempladas ofenden también derechos garantizados en las mismas convenciones internacionales generales ya señaladas y además otras específicas: la Convención sobre Esclavitud; las Convenciones Internacional e Interamericana contra la Tortura; el Convenio para la Represión de la Trata de Personas y de la Prostitución de Personas Ajenas; la Declaración para la Protección de todas las Personas contra las Desapariciones Forzadas (1992); la Convención Interamericana sobre Desaparición Forzada de Personas (1994); la Convención de las Naciones Unidas para la protección de todas las personas contra las desapariciones forzadas (2006); en fin, la Convención Internacional sobre la represión y el castigo del crimen de Apartheid (1973, e.v. 1976). La situación es ligeramente distinta en lo que se refiere a los crimenes de guerra (art. $8^{\circ}$ del Estatuto), ya que si bien muchos de ellos se superponen con los delitos de los artículos anteriores (muertes, lesiones, torturas, etc.), ellos aparecen referidos a los Convenios de Ginebra de 1949, la principal fuente regulatoria de los llamados usos y costumbres de la guerra, sucesores de las antiguas Convenciones de La Haya, y no a Tratados generales o Declaraciones específicas sobre Derechos Humanos; esto es, de la manera de hacer la guerra, especialmente en cuanto a las armas prohibidas, a los derechos de los prisioneros y al tratamiento de las poblaciones civiles. Pero tales infracciones aparecen vinculadas con una guerra o conflicto interno ya en progreso: no se refieren al derecho a hacer la guerra, los llamados crimenes contra la paz, que completan la trilogía de Nuremberg, y cuya infracción principal es el desencadenamiento y desarrollo de una guerra de agresión. Ese delito, nombrado como crimen de agresión, cae también bajo la competencia de la Corte conforme al art. $5^{\circ}$, pero como es sabido, ella no puede comenzar a ejercer su competencia hasta que los Estados Partes se pongan de acuerdo en la definición de tal crimen y en las condiciones 
en que la Corte podrá ejercer su competencia, la cual, se advierte, deberá ser compatible con las disposiciones pertinentes de la Carta de las Naciones Unidas. No nos corresponde ahora ahondar en este asunto pendiente, que es bastante complejo y no se ve próximo a una solución, pero dejaremos señalado que si un día se llega a acuerdo para definir el crimen de agresión, la comisión del mismo no podría ser vinculada con la violación de alguno de los actuales documentos internacionales sobre derechos humanos, puesto que ninguno de ellos considera como uno de tales derechos el derecho a la paz.

5. Desde el juicio de Nuremberg se han vertido críticas hacia la existencia del Derecho Penal Internacional mismo, algunas de las cuales se siguen repitiendo hasta ahora. Pero no cabe duda de que la situación ha ido evolucionando en el sentido de asimilar cada vez más las reglas del Derecho Penal Internacional a lo que son los derechos penales nacionales de tipo liberal. De los tribunales de Nuremberg y de Tokio se dijo que eran tribunales formados por los países vencedores de una guerra para juzgar a los dirigentes políticos y militares de los países vencidos. De los tribunales internacionales creados con posterioridad por las Naciones Unidas, como los de la ex Yugoeslavia y de Rwanda, ya no puede decirse lo mismo, puesto que no están integrados por jueces de países "vencedores" para juzgar a los "vencidos", pero subsiste la crítica de que son tribunales creados ex post facto para juzgar crímenes cometidos con anterioridad. En fin, de la Corte Penal Internacional no puede decirse ni una ni otra cosa: es un tribunal permanente, no designado por los vencedores de un conflicto para juzgar a los dirigentes vencidos, y no es creado ni por dependiente de un organismo político como las Naciones Unidas o su Consejo de Seguridad. Este último rasgo es particularmente importante, fue fuente de arduo debate en la Conferencia Diplomática Internacional de 1998 que creó la Corte y es probablemente una de las más poderosas razones por las cuales los Estados Unidos no han ratificado el Estatuto que la creó.

En lo demás, el Estatuto de Roma incorpora expresamente los principios del derecho penal liberal: el principio de legalidad, de irretroactividad, de responsabilidad penal personal, de la necesidad de culpa para poder ser condenado; el respeto a la cosa juzgada y al non bis in idem; de exclusión de juzgamiento para los menores de dieciocho años; el efecto de obrar bajo órdenes superiores; la exención de responsabilidad por error, de hecho o de derecho, y añade otros elementos propios de la naturaleza del Derecho Penal Internacional: la irrelevancia de los cargos oficiales que se hayan detentado, para eximir de responsabilidad o atenuarla; la llamada “responsabilidad por el mando' o de los jefes, militares o civiles, en crímenes cometidos por los subordinados, y la imprescriptibilidad de los crímenes que caen bajo la competencia de la Corte

En materia de penas, si bien no se sigue el sistema de asignar a cada infracción una pena específica determinada, las penas aplicables por la Corte están fuertemente restringidas. Ellas son: la reclusión hasta por 30 ańos; la reclusión perpetua para casos muy graves y calificados; la multa y el comiso. De este modo, si un crimen de la competencia de la Corte 
se comete en un Estado cuya legislación interna contempla la pena de muerte, resulta más conveniente para el acusado ser juzgado en la Corte Internacional que en los tribunales del país de comisión. Por otra parte, aunque el tiempo nos impide profundizar aquí en ello, el Estatuto se cuida de garantizar a los acusados todos los derechos generalmente aceptados para ejercer adecuadamente su defensa y gozar de un juicio imparcial, e incluso, lo que no es corriente en los países de sistema procesal acusatorio, tiene un derecho muy amplio de apelación para ante la Sala de Apelaciones de la propia Corte.

6. Finalmente, nos ocuparemos de las perspectivas que se advierten sobre el porvenir y utilidad de la Corte Penal Internacional para el castigo de los graves crímenes que caen bajo su competencia y lesionan los derechos humanos más fundamentales en gran escala.

A nuestro juicio, ello depende de dos factores igualmente importantes. El primero, obviamente, es la conducta de la propia Corte, que determinará, a su vez, el prestigio de que goce y que sepa formarse. De este aspecto nos ocuparemos al terminar nuestra intervención.

El segundo es el apoyo que la labor de la Corte pueda encontrar en los países del mundo. La Corte no tiene un cuerpo de policía propio, ni cárceles propias, ni otros medios coercitivos para proceder contra los acusados que deben ser llevados ante ella para juicio, y en todos esos aspectos depende exclusivamente de la cooperación que le presten los Estados Partes, en la reunión de las pruebas, la aprehensión de los acusados y el cumplimiento de las penas.

A este respecto, frente a la naturaleza de la Corte, dos concepciones se enfrentaron en la Conferencia de Roma. Para la primera, la Corte debería ser un "brazo judicial" dependiente de las Naciones Unidas, y más específicamente, de su Consejo de Seguridad, es decir, que juzgara solo los casos o los individuos que el Consejo le remitiera. Ello sería particularmente importante en caso de que la Corte juzgara por el crimen de agresión, dado que según la Carta de las Naciones Unidas, en el Consejo de Seguridad radica la facultad de declarar a un país "nación agresora", no para juzgar judicialmente la agresión, sino para tomar las medidas (que pueden llegar a ser hasta militares) para restablecer la paz y la seguridad. Pero como en el Consejo de Seguridad cualquier acuerdo requiere el voto favorable de los cinco miembros permanentes del mismo (Estados Unidos, Rusia, China, Reino Unido y Francia), esta situación pondría de partida a salvo de ser enjuiciados a los nacionales de cualquiera de esos países, a menos que estos consintieran en que sus súbditos fueran juzgados por la Corte. Pero el sentimiento predominante en los miembros de la Conferencia era diferente: se quería un Tribunal de justicia hecho y derecho, no dependiente para su labor de la voluntad de un organismo político, por respetable que fuera, como el Consejo de Seguridad. Esta fue la posición que en definitiva se impuso. La regla que se incorporó al Estatuto fue que una vez iniciada la labor de la Corte, el Consejo de Seguridad (art. 16) pudiera solicitar a la Corte la suspensión del procedimiento iniciado o por iniciarse, por un período de doce meses, renovable. Pero ese pedido de suspensión, como es un acuerdo 
del Consejo, debe también contar con el voto de todos los miembros permanentes. Basta, pues, con que uno solo de ellos se oponga, para que la petición no pueda ser formulada, o renovada, si es el caso.

Esta circunstancia motivó la inclusión en el Estatuto de dos disposiciones: una suspensiva y una escapatoria.

La disposición suspensiva es el art. 124, conforme al cual un Estado parte, al ratificar su calidad de tal, puede declarar que por un período de siete ańos (no renovables) de su adhesión, no aceptará la jurisdicción de la Corte respecto de los crímenes de guerra cometidos en su territorio o supuestamente por sus nacionales. Francia hizo uso de esa cláusula, y las razones que tuvo fueron claramente expresadas por el entonces presidente Chirac en respuesta a la Coalición Francesa por la Corte Penal Internacional:

"En respuesta a vuestra pregunta relativa al art. 124, os confirmo que Francia rechazará por un periodo transitorio la competencia de la Corte Penal Internacional por los crímenes de guerra. En efecto, la definición de los crímenes de guerra en el sentido del Estatuto es distinta de la de los crímenes contra la humanidad y el genocidio, en el sentido de que pueden ser cometidos por actos aislados. Denuncias sin fundamento y teñidas de segundas intenciones políticas podrían por lo tanto dirigirse contra el personal de países que, como el nuestro, están comprometidos en teatros exteriores, especialmente en el cuadro de operaciones tendientes al mantenimiento de la paz. La experiencia permitirá verificar la eficacia de las garantías integradas en el Estatuto para evitar tales desviaciones". (15 de febrero de 1999).

Se trata de una objeción sin ningún fundamento. Dada la primacía de la jurisdicción territorial o nacional, basta con que Francia, o cualquier otro país, en caso de una acusación de crimen de guerra contra uno de sus nacionales manifieste su intención de juzgarlo y luego lo haga con honestidad, para sustraerlo a la competencia de la Corte. Además, conforme a los arts. $1^{\circ}$ y $8^{\circ}$ del Estatuto, la Corte juzgará solo "los crímenes más graves de alcance internacional", y en lo relativo a los crímenes de guerra específicamente, "cuando esos crímenes se inscriban en un plan o una política o cuando formen parte de una serie de crímenes análogos cometidos en gran escala", y si se agrega que una de las causales de inadmisibilidad de un caso es que el crimen "no tiene la gravedad suficiente para que la Corte se ocupe de él”, lo que puede ser declarado de oficio por la Corte o impetrado por el Estado competente o por el propio acusado, se llegará a la conclusión de que es prácticamente imposible que un soldado francés sea llevado a juicio ante la Corte "por un acto aislado" en el curso de una operación de mantenimiento de la paz.

El otro artículo, que es de "escapatoria", es el 98, conforme al cual el compromiso general que tienen los Estados Partes de entregar a la Corte a las personas requeridas por esta 
para ser enjuiciadas, cesa cuando ese Estado tiene un compromiso con el Estado de nacionalidad del acusado, para no entregar a los nacionales de este último sin el consentimiento del mismo. Estados Unidos, aunque no es Estado Parte, ha presionado diplomáticamente a numerosos países (actualmente deben ser no menos de 50) para celebrar acuerdos de esta naturaleza, lo que pone a salvo a ciudadanos norteamericanos de ser entregados a la Corte para enjuiciamiento, sin el consentimiento previo de los Estados Unidos.

¿Por qué esa resistencia de Estados Unidos a suscribir el Estatuto de Roma y ratificarlo después? Hay incluso una ley que ordena suspender la ayuda económica a los países que rehúsen firmar con los Estados Unidos un acuerdo que haga aplicable el art. 98. Hasta se ha aprobado una resolución que declara legal cualquiera acción, incluyendo el uso de la fuerza, para liberar a los norteamericanos que estén en poder de la Corte Penal Internacional para ser juzgados.

El embajador David Scheffer, jefe de la delegación de Estados Unidos en la Conferencia de Roma de 1998, al advertir el curso que tomaban los debates, pronunció un discurso en el que manifestó que los Estados Unidos solo aprobarían el Estatuto a condición de que ningún ciudadano norteamericano pudiera ser procesado por la Corte sin el consentimiento del Gobierno norteamericano. Pero igual que en el caso de Francia, es obvio que si un ciudadano de los Estados Unidos llega a ser requerido para un proceso en la Corte, bastaría con que Estados Unidos manifestara su voluntad de someterlo él mismo a proceso y que luego lo hiciera seria e imparcialmente, para que el caso quedara radicado ante la justicia norteamericana.

La verdadera razón, no manifestada en el discurso del embajador Scheffer, y que explica incluso la política desconfiada y hasta abiertamente hostil de Estados Unidos para con la Corte, es el temor de que la Corte quede en manos de un fiscal tercermundista que se dedique a perseguir y a exponer públicamente a soldados u otros ciudadanos norteamericanos, acusándolos de crímenes bajo la competencia de la Corte, aunque en definitiva los juzguen los propios Estados Unidos, pero habiéndose creado un escándalo propagandístico para desacreditar a los Estados Unidos. Pero ese temor es infundado en teoría y se ha mostrado infundado en la práctica. Lejos de estar en manos del fiscal, la Corte tiene una serie de controles muy estrictos sobre sus actividades y en el hecho los ha ejercido. No es el caso de explicarlos aquí en detalle. La composición de la Corte garantiza que sus integrantes son personas calificadas, de vasta experiencia y de repartición geográfica equitativa.

El 31 de diciembre del año 2000, el entonces presidente Clinton suscribió el Estatuto de Roma. Posteriormente, el Gobierno de los Estados Unidos advirtió que no haría nada por ratificarlo. Y en mayo de 2002, bajo la presidencia de George W. Bush, Estados Unidos notificó al secretario general de las Naciones Unidas que no se sentía ligado por el Estatuto de Roma, y en una actitud hasta entonces desconocida en derecho internacio- 
nal, "retiró" la firma del presidente Clinton, y luego manifestó que no daría ninguna clase de apoyo para que la Corte llegara a funcionar (lo que, sin embargo, ocurrió en 2002) ni tampoco trabajaría con otras naciones para modificar el Estatuto de manera de poder aprobarlo.

Esto pone en realidad a Estados Unidos en la paradójica situación de haber sido el principal motor detrás de los tribunales internacionales y juicios de postguerra (Nuremberg y Tokio; Ex Yugoslavia y Rwanda) y, sin embargo, oponerse tan decididamente a un tribunal cuyo Estatuto supera con mucho el de los precedentes tribunales y cuyo recto funcionamiento sería una herramienta poderosísima para prevenir y sancionar los más graves crímenes contra los derechos y la conciencia internacionales.

No deja de ser significativo que el propio embajador Scheffer, el mismo que representó a los Estados Unidos en Roma y que hizo el discurso de rechazo para el Estatuto, haya escrito, en 2000, un artículo en que dice textualmente:

"El mundo está cambiando. La Corte Penal Internacional quedará establecida pronto. Debemos decidir si estamos a favor del imperio del derecho o si lo esquivamos. Si no podemos defender la posición de que los más odiosos crímenes contra la humanidad serán combatidos y que debemos construir las instituciones que se encarguen de ello en un mundo muy complejo, entonces nuestro liderazgo en promover el imperio del derecho en el mundo declinará rápidamente y el valor de nuestros propios principios desaparecerá. Otros tomarán la delantera”.

7. Para terminar, señalaremos que hay indicios de que esta situación pueda estar cambiando favorablemente. Dos acontecimientos son indicio de ello. Sobre ellos hay un comentario extenso en el Anuario de Derechos Humanos publicado por el Centro de Derechos Humanos de nuestra Facultad, correspondiente al año 2009, del que somos autores en colaboración con la doctora Claudia Cárdenas.

Se trata del caso del primer imputado que fue detenido y llevado a proceso ante la Corte, Thomas Lubanga, de nacionalidad congolesa, acusado de crímenes de guerra, particularmente de la utilización de menores de edad en actividades bélicas. Un primer rasgo importante en su caso es que de las cuatro situaciones de que se ocupa actualmente la Corte (Uganda, República Democrática del Congo, República Centroafricana y Sudán-Darfur), una le ha sido remitida por el propio país donde han ocurrido los hechos delictivos, que considera así que sus tribunales nacionales no están en situación de resolver adecuadamente esos casos, y confían más en la Corte para que lo haga: un respaldo a nuestro juicio muy significativo y es precisamente el de la República Democrática del Congo.

Pero además el caso de Lubanga es importante por otra razón, que demuestra el funcionamiento imparcial de la Corte y que ejerce adecuadamente sus funciones de con- 
trol sobre la actividad del fiscal. El proceso avanzó hasta llegar al estado de juicio, cuando se produjo un incidente con motivo de que piezas documentales de cargo que el fiscal había obtenido, lo habían sido bajo un estatuto de confidencialidad según lo establecido en el art. 54 del Estatuto, y mientras el fiscal sostenía que no podía facilitarlas a la defensa, porque existía el compromiso de confidencialidad, la defensa alegaba que el contenido de esos documentos era esencial para una defensa adecuada y debía dársele conocimiento de los mismos. La Sala 1 de Primera Instancia resolvió el conflicto y decidió que debía ponerse en libertad a Lubanga, porque al no tener acceso su defensa a tales documentos, no podía haber un debido proceso. De los tres jueces de la Sala, dos eran latinoamericanos: René Blatmann, de Bolivia y Elizabeth Odio, de Costa Rica. La resolución fue apelada y entretanto se obtuvo una apertura parcial de la fuente de origen de los documentos (Naciones Unidas), para facilitar a los jueces el acceso a los documentos, y por su intermedio, a la defensa. Luego, la Sala 1 de Apelaciones rechazó la solicitud del fiscal de ir inmediatamente a juicio oral, y en cuanto a la libertad de Lubanga, devolvió al asunto a la Sala de Primera Instancia para que resolviera nuevamente a la luz de la nueva situación. Este asunto, tratándose de un caso tan emblemático como del primer detenido a disposición de la Corte y primer enjuiciado, es una muestra muy elocuente de la independencia de la Corte frente al fiscal, y de su preocupación por el respeto de las normas del debido proceso.

La segunda situación -y con esto terminamos- es la relativa a Sudán-Darfur. No entraremos aquí en las complejidades del caso, aparte del hecho innegable de que en esa provincia o región de Sudán existe desde hace años un conflicto alentado por el Gobierno de Sudán en que las matanzas, persecuciones y creación de condiciones de vida insoportables han sido claras para la comunidad internacional. Pues bien, el Consejo de Seguridad de Naciones Unidas, órgano responsable de la paz y seguridad internacionales, decidió remitir el caso (o la "situación" como se dice en el vocabulario del Estatuto) a la Corte Penal Internacional, ¡sin la oposición de los Estados Unidos, miembro permanente del Consejo, con derecho a veto, que no es parte del Estatuto de Roma y decidido adversario de su aprobación! Esto es para nosotros la muestra más evidente de que algo está cambiando respecto a la Corte Penal Internacional, tanto para el escepticismo de quienes son sus partidarios, como de la desconfianza de quienes son sus adversarios.

La intervención de la Corte en el caso de Sudán-Darfur no ha podido ser más enérgica y ha creado un precedente que sin duda contribuirá a su prestigio. El 14 de julio de 2008 el fiscal de la Corte solicitó la aprobación de la Sala de Cuestiones Preliminares, conforme al Estatuto, de la detención del presidente de Sudán, Omar al-Bashir, por los cargos de genocidio, crímenes de lesa humanidad y crímenes de guerra. La Sala de Cuestiones Preliminares aprobó la solicitud del fiscal, aunque excluyó de la orden de detención el cargo de genocidio y la limitó a los crímenes de lesa humanidad y crímenes de guerra. Por cierto que al-Bashir, en pleno ejercicio del poder, manifestó su público rechazo de la orden de detención y su de- 
cisión de no someterse a ella. Ha habido quienes sostienen que esta situación puede entorpecer un proceso de paz en Sudán, pero esas alegaciones parecen infundadas si se considera que es precisamente el organismo por excelencia encargado de velar por la paz y seguridad del mundo, el Consejo de Seguridad de las Naciones Unidas, el que ha remitido el caso a la Corte, lo que hace presumir que no estimará que tal intervención ponga en peligro la paz y seguridad.

Mientras al-Bashir siga en el poder, será ilusorio poder arrestarlo. Pero las situaciones políticas no son eternas, y los crímenes de competencia de la Corte son imprescriptibles. 


\section{REFERENCIAS BIBLIOGRÁFICAS}

Acuerdo y Estatuto del Tribunal Militar Internacional de Nuremberg.

Estatuto del Tribunal Internacional para la ex Yugoslavia

Estatuto del Tribunal Internacional para Rwanda.

Estatuto de la Corte Penal Internacional. [Citado 10 de agosto de 2010] Disponible en la World Wide Web: <http://www.icc-cpi.int/library/about/officialjournal/Rome_Statute_Spanish.pdf>

Reglas de procedimiento y prueba la Corte Penal Internacional. [Citado 10 de agosto de 2010] Disponible en la World Wide Web: <http://www.icc- cpi.int/library/about/officialjournal/Rules_of_procedure_and_ Evidence_Spanish.pdf>

La Corte Penal Internacional, elementos de los crímenes. [Citado 10 de agosto de 2010] Disponible en la World Wide Web: <http://www.icc-cpi.int/library/about/officialjournal/Element_of_Crimes_Spanish.pdf>

Convenciones de Ginebra de 1949 y Protocolos Adicionales de 1977 y 2005. [Citado 10 de agosto de 2010] Disponible en la World Wide Web: <http://www.icrc.org/Web/spa/sitespa0.nsf/htmlall/section_ihl_ databases?OpenDocum ent>

Амвos, Kai. "Cumplimiento de órdenes e Impunidad". En su: Impunidad y Derecho Penal Internacional. Buenos Aires, Argentina: Ediciones Ad-Hoc, 1999.

Temas del Derecho Penal Internacional. Bogotá, Colombia: Ediciones Universidad Externado de Colombia, 2001.

La Parte General del Derecho Penal Internacional. Montevideo, Uruguay: Ediciones Fundación Konrad Adenauer, 2004.

El Nuevo Derecho Penal Internacional. Lima, Perú: ARA Editores, 2004.

Аmbos, Kai y Guerrero, Óscar (comp.). El Estatuto de Roma de la Corte Penal Internacional. Bogotá, Colombia: Ediciones Universidad Externado de Colombia, 1999.

Arroyo, Luis y Nieto, Adán. Código de Derecho Penal Europeo e Internacional. Madrid, España: Ed. UCLM y Ministerio de Justicia, 2008.

Barros van Buren, Mario. El Derecho a la Guerra. Santiago, Chile: Ediciones Universidad Católica, 1959.

Bujosa Vadell, Lorenzo. La cooperación procesal de los Estados con la Corte Penal Internacional. Barcelona, España: Atelier, 2008.

Cárdenas Aravena, Claudia. "Los Crímenes del Estatuto de la Corte Penal Internacional en el derecho chileno, necesidad de una implementación”, en: Revista Politica Criminal No 2/2006, pp. 1-17. Santiago, Chile.

"La Corte Penal Internacional y su relación con las jurisdicciones nacionales: El principio de complementariedad“, en: Revista de Magister y Doctorado en Derecho. Santiago, Chile: Universidad de Chile. No 1/2007, pp. 123-138.

“Antecedentes y proceso de negociación de la Corte Penal Internacional”. En: Corte Penal Internacional: Condiciones políticas, jurídicas y ciudadanas para la ratificación del Estatuto de Roma. Santiago, Chile: Andros Impresores, 2008, pp. 27-35.

"Principios, características y mecanismos de activación de la Corte Penal Internacional". En: Corte Penal Internacional: Condiciones políticas, jurídicas y ciudadanas para la ratificación del Estatuto de Roma. Santiago, Chile: Andros Impresores, 2008, pp. 37-43.

Eiroa, Pablo. La Corte Penal Internacional: Fundamentos y Jurisdicción. Buenos Aires, Argentina: Ediciones AdHoc, 2004. 
Etcheberry, Alfredo y Cárdenas, Claudia. “La Corte Penal Internacional: abriendo caminos”, en: Anuario de Derechos Humanos, 2009; Santiago, Chile: Centro de Derechos Humanos, Facultad de Derecho, Universidad de Chile.

GiL, Alicia. Derecho Penal Internacional. Madrid, España: Editorial Tecnos, 1999.

Gómez de Liaño, Francisco Javier (comp.). Legislación Penal Internacional. Madrid, España: Ediciones Colex, 1991.

Gramajo, Juan Manuel. El Estatuto de la Corte Penal Internacional. Buenos Aires, Argentina: Editorial Abaco, 2003.

IвáÑez, Augusto. El Sistema Penal en el Estatuto de Roma. Bogotá, Colombia: Ediciones Universidad Externado de Colombia, 2003.

Lledo, Rodrigo. Derecho Internacional Penal. Santiago, Chile Editorial Congreso, 2000.

Quesada Alcalá, Carmen. La Corte Penal Internacional y la soberanía estatal. Valencia, España: Tirant lo Blanch y Cruz Roja Espańola, 2005.

Ramella, Pablo. Crimenes contra la Humanidad. Buenos Aires, Argentina: Ediciones Depalma, 1986.

Werle, Gerhard. Tratado de Derecho Penal Internacional. Valencia, España: Tirant lo Blanch, 2005.

Zuppi, Aberto. Jurisdicción Universal para Crimenes contra el Derecho Internacional. Buenos Aires, Argentina: Ediciones Ad-Hoc, 2002. 